\title{
A low-temperature attachment for a four-circle neutron diffractometer
}

\author{
A SEQUEIRA, SANDHYA BHAKAY-TAMHANE and S R SAWANT* \\ Neutron Physics Division, *Physics Group Workshop, Bhabha Atomic Research Centre, \\ Trombay, Bombay 400085 , India \\ MS received 29 September 1986

\begin{abstract}
A single-stage closed-cycle helium gas cryogenerator, capable of cooling between $77 \mathrm{~K}$ and $300 \mathrm{~K}$, has been installed on the 4-circle neutron diffractometer at CIRUS. The cryo-tip assembly has been incorporated directly on the $\varphi$-circle of the full-circle crystal orienter in place of the goniometer head used in room temperature experiments. The salient features of this low-temperature attachment and its performance are discussed.
\end{abstract}

Keywords. Low temperature diffraction; diffractometer cryo-assembly; helium gas cryo-tip; closed-cycle cryogenerator.

\section{Introduction}

Any cryostat mounted on a conventional four-circle diffractometer (with an Eulerian cradle) must be capable of tilting atleast $90^{\circ}$ off the vertical and work for long periods without interruption. This places severe limitations on the type of cryotips used on these diffractometers. A number of different cryo-systems for use on $\mathrm{x}$ ray/neutron single-crystal diffractometers have been reported; the various methods (see table 1) can be broadly classified (Rudman 1976) into: (a) gas stream i.e. a stream of cold gas (He, $\mathrm{N}_{2}$ or air) is directed over the sample, (b) conduction i.e. the sample is cooled by means of a good thermal conductor (cold finger) in contact with a cooling unit; the cooling unit may be a cold bath, mechanical refrigerator, thermoelectric cooler, Joule-Thomson expansion device or a closed-cycle cryorefrigerator and (c) immersion, where the entire camera is immersed in cold liquid or cold liquid is dripped over sample.

The immersion method does not allow a fine temperature control. The gas stream method (Lippman and Rudman 1976; Burbank 1973), though easily adaptable to any instrument, is not so convenient due to the cumbersome nature of cryogen handling (liquid $\mathrm{N}_{2}$ or compressed gas), temperature instability during cryogen refilling and frosting problems, which persist even with proper insulations during the actual working of a cryo-system over prolonged periods of time as in neutron diffraction.

The conduction cooling apparatus with liquefied gasses (Coppens et al 1974) was not favoured as the levels of performance of these systems seem to be directly proportional to their cost and complexity. Thermoelectric coolers (working on the Seebeck-Peltier thermoeffect), though very clean and simple to operate, are capable of cooling to only $-45^{\circ} \mathrm{C}$ with a single-stage (Agron et al 1972) and to $-80^{\circ} \mathrm{C}$ with multi-stages (Khan and Erickson 1970) and hence are of limited use. Alternately, selfregulating Joule-Thomson coolers are also not convenient to use, due to the stringent requirements on the purity and dryness of gas, the cleanliness of gas lines and the open cycle nature of the operation.

The introduction of closed-cycle cryo-refrigerators has made available a new range of cryogenic devices inexpensive in use and simple to operate, as against the earlier 
Table 1. Different cryo-systems in use.

\begin{tabular}{|c|c|}
\hline Type of apparatus & Manufacturers \\
\hline Gas stream cooling apparatus & $\begin{array}{l}\text { Enraf-Nonius, Netherlands; Philips X-ray Instru- } \\
\text { ments, Netherlands; Rich Seifert, West Germany; } \\
\text { Syntex Analytical Instruments, USA; Techsna- } \\
\text { bexport, USSR. }\end{array}$ \\
\hline $\begin{array}{l}\text { Conduction cooling with liquid } \mathrm{N}_{2} \\
\text { or liquid He continuous-flow cry- } \\
\text { ostats. }\end{array}$ & $\begin{array}{l}\text { Air-Products and Chemicals USA; Cryogenic } \\
\text { Associates, USA; Oxford Instruments, UK. }\end{array}$ \\
\hline Thermoelectric coolers & $\begin{array}{l}\text { Borg-Warner Corp., USA; Jepson Thermo- } \\
\text { electrics, USA; Cambion Thermoelectrics, USA. }\end{array}$ \\
\hline Self-regulating $\mathbf{J}-\mathrm{T}$ coolers & $\begin{array}{l}\text { Hymatic Engineering, UK; Air-Products and } \\
\text { Chemicals, USA. }\end{array}$ \\
\hline Closed-cycle cryo-refrigerators. & $\begin{array}{l}\text { Air-Products and Chenicals. USA; Custom-built } \\
\text { according to specified requirements. }\end{array}$ \\
\hline
\end{tabular}

cryo-systems which have liquids as refrigerants or are somewhat uneconomical in prolonged operations. Further, the cold-tip is so compact that its adaptation on a full-circle diffractometer is not a problem; with minor modifications the same design can be used on a $x$-ray diffractometer. The cryo-tip opted for was a compact singlestage Air-Products DISPLEX (model CS-1003) closed-cycle cryo-system capable of cooling in the range $45-300 \mathrm{~K}$. The DISPLEX system is a closed-cycle cryogenerator, consisting of a single-stage displacer/expander cooler, a compact air-cooled, oillubricated compressor module with integral oil clean-up package and electrical controls. The compressor is connected to the valve assembly with flexible metal lines, the valve assembly in turn is connected to the displacer/expander cold end with more flexible nylon tubings. $\mathrm{M} / \mathrm{s}$. Air-Products have modified the cold head, embedding a standard $30 \mathrm{Watt}$ heater and chromel/gold (0.07 atomic\% iron) thermocouple according to our requirements and supplied a compatible temperature controller. The refrigeration capacity of the cooler is $1 \mathrm{~W}$ at $77 \mathrm{~K}$. A two-stage DISPLEX cooler was not favoured as the system is not as compact as a single stage one and could not be incorporated on our diffractometer.

\section{General description}

The neutron diffractometer (Sequeira et al 1978) has a $45 \mathrm{~cm}$-dia full-circle crystal orienter which is sturdy enough to carry a cryostat. The single-stage displacerexpander is mounted directly on the $\varphi$-circle of the Eulerian cradle. A schematic drawing of the displex-cryo-tip assembly (similar to the ILL, Grenoble assembly (Allibon et al 1981)) as incorporated on the $\varphi$-circle of the full-circle Eulerian cradle is shown in figure 1 . The total height of the cryo-tip is $\sim 10.1 \mathrm{~cm}$ while the space available on the $\chi$-circle is $\sim 10.6 \mathrm{~cm}$. Thus no vertical adjustment has been provided for the cold tip. The crystal is mounted directly on the cryo-tip using OFHC copper mounting studs of $\sim 2-3 \mathrm{~mm}$ height; the exact height of the stud is matched so that the centre of the sample crystal comes to the centre of the full circle. The crystal orientation is determined directly (without goniometer head) using optimized $\chi$ and $\varphi$ angles for a few reflections. The $\varphi$-motion entails the rotation of the cryo-tip on 


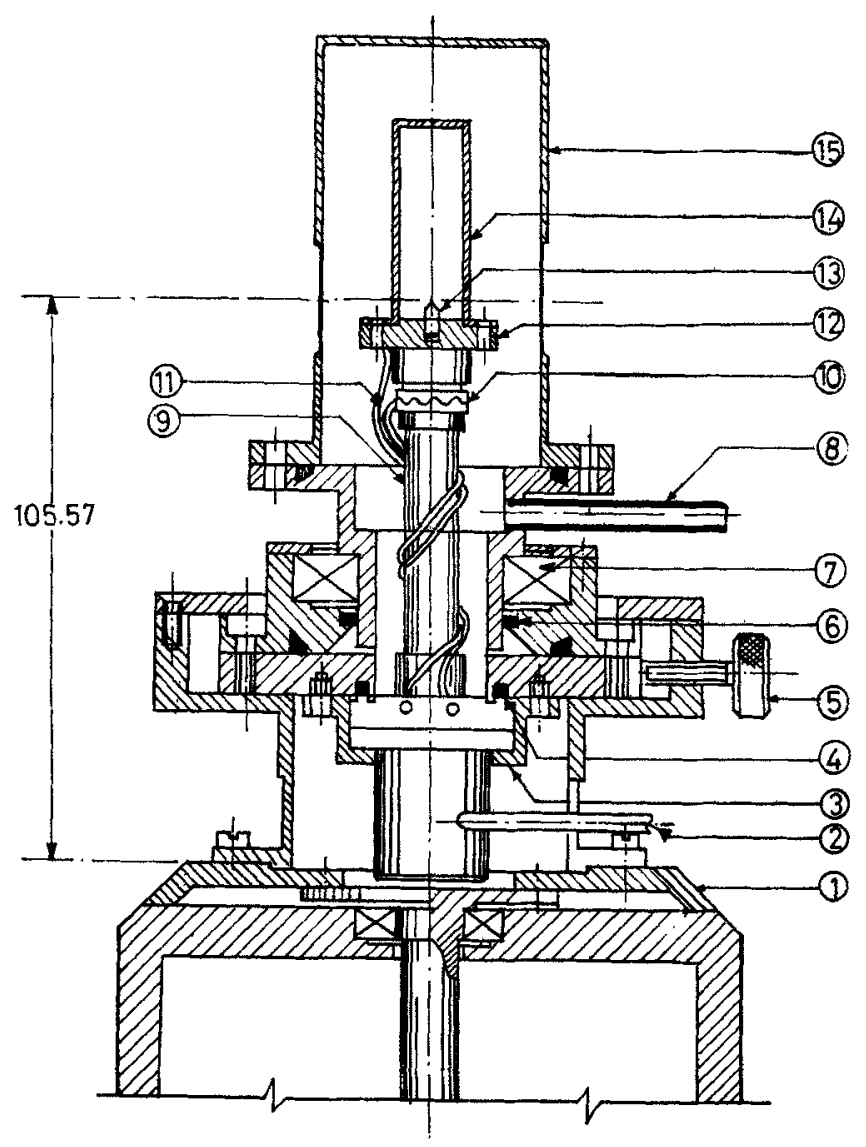

Figure 1. A schematic drawing of the displex cryo-tip assembly as incorporated on the $\varphi$ circle of the neutron full circle crystal orientor. The parts indicated are the $\varphi$-drive box (1), helium lines to/from cold head (2), split-cup which provides rigid support to cryo-tip and isolates the vacuum chamber from the lower half of the assembly (3), teflon O-ring (4), lateral translation screws (5), rotary vacuum seal (6) and ball-bearings (7) for decoupling the $\varphi$-rotation from vacuum pumping port (8) and vacuum shroud (15). The DISPLEX CS-1003 cryo-tip (9) has a heater (10) and a thermocouple (11) embedded in the cold head flange (12). The centre of the diffractometer (13), the inner (14) and outer (15) aluminium vacuum shrouds are also indicated. The cold finger is of OFHC copper; all adapter parts are fabricated using anti-magnetic SS-304.

which the crystal has been mounted. The $\varphi$-rotation is decoupled from the vacuum port and vacuum shroud by use of a rotating vacuum seal and ball-bearing to avoid mechanical instabilities arising from a rotating vacuum port. This places limitations on the ultimate vacuum reached $\left(>10^{-4}\right.$ torr). A simple rotary pump does the task within half an hour.

Figure 2 shows the various components (valve-motor, cables, gas lines and vacuum inlet) placed to avoid excessive twisting of the lines, fouling up of the moving parts of the diffractometer by cables or lines or obstructing the incident and diffracted beams of neutrons. The rotation of $\varphi$ has to be limited to $300^{\circ}$ both by hardware as well as software to avoid twisting of the nylon tubing connecting the cold head to the valve motor assembly. The vacuum port and the external vacuum shroud is held in place by using two clamps which hold on to the $\chi$-ring. 


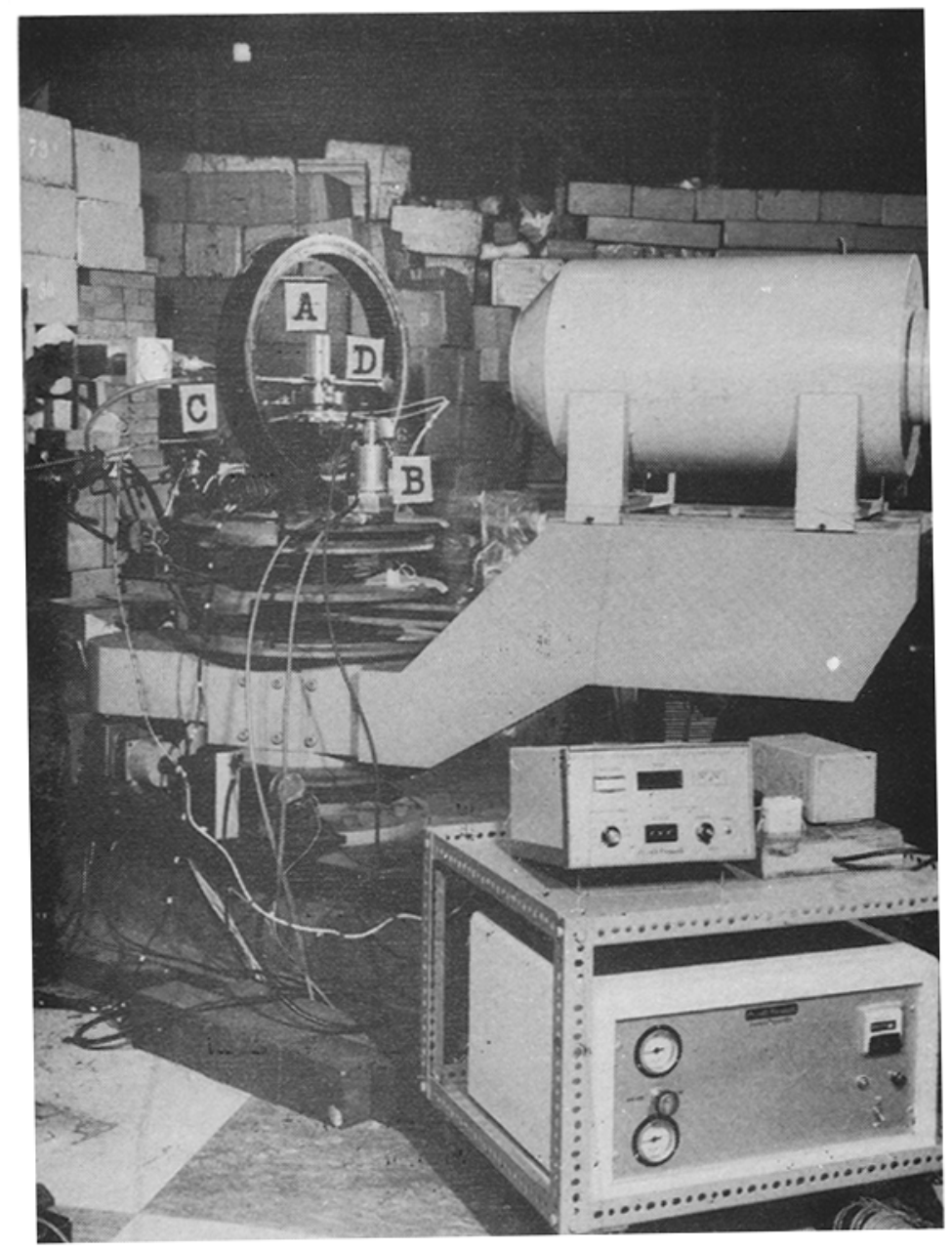

Figure 2. Photograph of the lou-temperature assembly after installation on the four-circle diffractometer. (A) is the vacuum shroud over the cryo-tip, (B) is the valve assembly held onto the (")-plate of the diffractometer. (C) is the vacuum port and (D) are the clamps which hold onto the $y$-circle. The compressor and temperature controller are placed on a trolley, visible in the foreground. The positions of all the components are optimized to minimize the twists'strains on the tubes and possible entangling with the diffractometer moving parts.

The heat and vacuum shields are made of $\mathrm{Al}$; both shields are designed in the $\mathrm{fc} \cdot \mathrm{m}$ of cylinders $\sim 0.5 \mathrm{~mm}$ thick. The external heat shroud has been ground to $\sim 0.3 \mathrm{~mm}$ to provide a window in the region where the beam is incident. In $x$-ray diffractometer the vacuum shields will have to be preferably of $\mathrm{Be}$ so as to be invisible' to $\mathrm{x}$ ray radiation.

\section{Use and performance}

As the positions of all the components have been determined the mounting of the low-temperature device onto the diffractometer can be accomplished within $10 \mathrm{~min}$. The sample is mounted directly on the cryo-tip using a mounting stud of suitable height and the crystal laterally centred using the lateral adjustments before mounting 
the vacuum shields. The $\mathrm{Cu}$ cold tip which falls within the beam area has to be covered with $\mathrm{Cd}$ to minimize the contamination and background scattering.

The space between the inner and outer vacuum shields is pumped till a vacuum of better than $10^{-3}$ torr is obtained and cooling is then started. The system cools to $130 \mathrm{~K}$ in about $1 \mathrm{hr}$ and to $\sim 80 \mathrm{~K}$ in approximately $2 \mathrm{hr}$. The cooling curve is nearly exponential. Temperature control is achieved by using the resistance heater embedded in the cold head along with the chromel/gold (iron) thermocouple and the temperature controller unit. The temperature indicator displays temperature on a 4digit readout, the resolution is $0.1 \mathrm{~K}$ and the stability $\pm 0.5 \mathrm{~K}$. The calibration was done using the room temperature, liquid nitrogen and dry ice temperatures. Though the low temperatures match perfectly well (within $\pm 1^{\circ}$ ), the room temperature display is off by $10^{\circ}$ and remains so even with all the zero and span adjustments. The low temperature calibration points, however, reproduce themselves.

The assembly is extremely simple to use and can be used without interruption for long periods. The charging of the system with commercial-grade helium gas has to be done once in approximately six months (nominal He-gas pressure 115 psi). Longterm measurements (as required in neutron diffraction experiments) are not possible at temperatures below $90 \mathrm{~K}$ as accurate temperature control becomes a problem. Also, if the compressor is used continuously for very long periods (exceeding a month or so), the temperature starts wandering. Further, continuous long usage of the compressor increases the risk of oil cross-over from the compressor; hence regular servicing of the cold head assembly is necessary. The filters installed in the compressor module must also be changed periodically.

The installation of the device introduces limits on the $\chi$ and $\varphi$ angles in addition to the intrinsic blind areas of the diffractometer. The $\chi$ accessibility has been nominally restricted to the range $-10^{\circ}<\chi<100^{\circ}$ and $\varphi$ accessibility to the range $45-300^{\circ}$. Even with these restrictions on the diffractometer angles, half the reciprocal space is accessible for crystals of all space groups other than the triclinic. The facility has so far been used to record over 1500 reflections in five low-temperature data sets to investigate the low-temperature structural phase transitions in $\mathrm{LiKSO}_{4}$ (BhakayTamhane and Sequeira 1986).

\section{Acknowledgement}

We are grateful to Dr R Chidambaram for useful suggestions and encouragement.

\section{References}

Agron P A, Levy H A and Bogardus B J 1972 J. Appl. Crystallogr. 5432

Allibon J R, Filhol A, Lehmann M S, Mason S A and Simms P 1981 J. Appl. Crystallogr. 14326

Bhakay-Tamhane S and Sequeira A 1986 Ferroelectrics 69241

Burbank R D 1973 J. Appl. Crystallogr. 6437

Coppens P, Ross F K, Blessing R H, Cooper W F, Larsen F K, Leipoldt J G, Rees B and Leonard R 1974 J. Appl. Crystallogr. 7315

Khan D C and Erickson R A 1970 Rev. Sci. Instrum. 41107

Lippman R and Rudman R 1976 J. Appl. Crystallogr. 9220

Rudman R 1976 'Low temperature x-ray diffraction': Monographs in low-temperature physics (New York: Plenum)

Sequeira A, Momin S N, Rajagopal H, Soni J N, Chidambaram R, Dilip Kumar, Ramana Rao A and Gopu V M 1978 Pramana-J. Phys. 13223 